\title{
AMIZADE E MILITARISMO: \\ UMA ANÁLISE DAS RELAÇÕES INTERPESSOAIS ENTRE OS MILITARES DAS GUARNIÇŌ̌ES DE COMBATE A INCÊNDIO DO 1ํ BATALHÃO DE BOMBEIROS MILITAR NA PARAÍBA
}

\author{
Maurício Maia Cavalcanti ${ }^{1}$ \\ Fábio Gomes de França²
}

\section{RESUMO}

Apresentamos neste artigo um estudo sobre as relações interpessoais de amizade e camaradagem entre indivíduos integrantes das guarnições do serviço operacional do Corpo de Bombeiros Militar da Paraíba (CBMPB). Os laços criados a partir dessas relações, muito embora tenha o CBMPB em sua estrutura organizacional os preceitos da hierarquia e disciplina, podem se estender para além dos muros dos quartéis e gerar uma transformação no ambiente de trabalho, proporcionando uma unidade para a equipe de trabalho, através do espírito de corpo. Nesse sentido, utilizamos a perspectiva teórica de Goffman, com ênfase na análise dos fenômenos da interação social, a partir dos quais realizamos uma pesquisa de campo, por meio da aplicação de um questionário aberto, a fim de confrontar os dados teóricos com a visão dos militares integrantes da atividade fim da Corporação.

Palavras-chave: relações interpessoais, interação social, amizade, camaradagem.

\footnotetext{
${ }^{1}$ Capitão do Corpo de Bombeiros Militar da Paraíba. Especialista em Segurança Pública Centro de Estudos PMPB. Email: maiacanti@yahoo.com.br

2 Capitão da Polícia Militar da Paraíba. Doutor em Sociologia - UFPB. Email: filhosdalegiao@gmail.com
} 


\title{
FRIENDSHIP AND MILITARISM: \\ AN ANALYSIS OF INTERPERSONAL RELATIONSHIPS \\ BETWEEN THE MILITARIES OF FIRE FIGHTING LININGS OF THE 1ST MILITARY FIRE BATTALION IN PARAIBA
}

\begin{abstract}
This article presents an study about interpersonal relations of friendship and camaraderie between individuals that are part of groups of operational service from the Paraíba Military Fire Department. The ties that are created from this relations, although the Paraíba Military Fire Department in his organizational structure have the precepts of hierarchy and discipline, may extended beyond the walls of the military units and create a transformation in work environment, providing a cohesion for the team, throught the team-work spirit. In this sense, we use theoretical perspectives of Aristotle, Goffman, Foucault and França, with emphasis in analysis of social interaction phenomenon, from which are conducted a field research, though a open questionnaire, in order to confront theoretical data with the vision of the military members from operational service of the corporation.
\end{abstract}

Key words: interpersonal relations, social interaction, friendship, camaraderie.

Artigo recebido em 16/11/16 e Aceito em 26/12/16. 


\section{INTRODUÇÃO}

O legado deixado pelos gregos, desde a Antiguidade, pode ser percebido especialmente no campo do conhecimento, com destaque para a filosofia em áreas como a ética e a estética, além de importantes contribuições para o pensamento político ocidental. Neste cenário, por uma perspectiva filosófica, temas sobre conhecimento, verdade, amor e amizade foram abordados pelos gregos. No entanto, a amizade é assunto recorrente, tendo sido citado por Platão em seu diálogo Lísis. Mas foi seu discípulo Aristóteles, em sua obra Ética a Nicômaco, quem disse que "a amizade é uma virtude, ou está conectada à virtude, além de ser algo extremamente necessário à vida. Mesmo que alguém possuísse todos os bens possíveis, se não possuísse amigos, ninguém apreciaria a vida" (1984, p. 179).

Segundo a visão de Epicuro, a amizade diz respeito aos homens comuns e não aos raros, de modo que os primeiros buscavam praticar o bem em favor dos outros não deixando ao mesmo tempo de pensar em si próprios. $\mathrm{Na}$ visão do filósofo, a amizade, além de ser uma característica um tanto comum, é também uma força motriz, que movimenta e conduz as atitudes e comportamentos do ser humano. Observamos assim que a amizade, na Antiguidade, era concebida como virtude dos homens, que procuravam fazer algo de bom de suas próprias vidas, trazendo à tona seus desejos éticos de comportamento e relacionamentos com seus semelhantes, e ainda, com a própria existência.

Reportando-nos ainda à Antiguidade, podemos entender, por exemplo, como os soldados do período se mantinham unidos em um ideal no campo de batalha, não só pelo objetivo do exército de sobrepujar o inimigo, mas também pelas relações de amizade e amor que cada integrante sentia pelos seus comandantes, seus comandados, por sua terra natal, por suas famílias, seus entes mais queridos e seus companheiros de batalha (GROS, 2009). Ao 
contrário, na Modernidade, após o século XVIII, a amizade dentro das instituições militares se desdobra por outras conotações. Ela é ao mesmo tempo uma ferramenta utilizada pelos comandantes para fortalecer o espírito de seus soldados e também o todo que se forma pelas porções individuais daqueles que o compõem. Nesse aspecto, a disciplina possui papel fundamental na moldagem do indivíduo, e dessa forma "não é mais simplesmente uma arte de repartir os corpos, de extrair e acumular o tempo deles, mas de compor forças para obter um aparelho eficiente" (FOUCAULT, 2014).

Assim sendo, somos levados a crer que o objetivo das instituições disciplinares na Modernidade, como nos aponta Foucault (2014), diz respeito à criação de laços entre os indivíduos de modo condicionado, o que se traduz no "espírito de corpo". Com uma visão análoga, podemos entender a partir de Goffman (2001) que os integrantes de uma instituição total, sejam eles da equipe de dirigentes ou da equipe de internos, obrigatoriamente, e devido ao contato diário, serão levados a se relacionar invariavelmente com indivíduos submetidos às mesmas condições institucionais, além de estarem separados não só fisicamente, mas moralmente do restante da sociedade.

É nesse ponto que surge a grande questão que nos faz refletir: é possível que, em meio a este ambiente controlado, possam ser criados laços de amizade que se fortaleçam e sejam levados a sobreviver fora dos limites das instituições? E de que forma essas relações interpessoais podem repercutir no cotidiano pessoal e profissional desses indivíduos? Neste ponto, vislumbramos neste artigo analisar as relações interpessoais que formam laços de amizade e camaradagem entre indivíduos inseridos em instituições militares, em especial no grupo pesquisado, composto por militares das guarnições operacionais de combate a incêndio do $1^{\circ}$ Batalhão de Bombeiros Militar da Paraíba. 
Revista Científica do Corpo de Bombeiros Militar de Pernambuco

Seção 1 - Artigos Técnico Científicos

Artigo publicado no Vol.03 №06 - Edição de JAN a JUN 2017 - ISSN 2359-4829

Versão on-line disponível em: http://www.revistaflammae.com

Nesse percurso, mostraremos como se estabelecem, a partir das interações sociais, as relações humanas numa sociedade organizada institucionalmente. A posteriori, tentaremos evidenciar a importância dos laços de amizade e camaradagem no mundo militar, contrapondo-se às concepções estigmatizadas de um regime disciplinador e hierárquico. E, por fim, verificaremos se os laços de amizade e camaradagem entre militares das guarnições de combate a incêndio são levados além dos limites da instituição e, se repercutem diretamente para os resultados profissionais da atividade fim. ${ }^{3}$

\section{A AMIZADE COMO RESULTADO DE INTERAÇÕES SOCIAIS}

Quando falamos em qualquer espécie de sociedade, logo recobramos a ideia de um grupo organizado de pessoas que compartilha de regras e ideais, os quais são fortes o suficiente para permitir a vida em conjunto. Nesse contexto, é inevitável que aconteçam contatos entre os indivíduos.

Quando um indivíduo chega à presença de outros, estes, geralmente, procuram obter informação a seu respeito ou trazem à baila a que já possuem. Estarão interessados na sua situação socioeconômica geral, no que pensa de si mesmo, na atitude a respeito deles, capacidade, confiança que merece, etc. (GOFFMAN, 2002, p. 11).

Essas informações sobre a situação em que se encontra o outro se mostram importantes na construção do Eu Social, ou seja, "a informação a respeito do indivíduo tem utilidade para definir a situação do encontro, tornando os outros capazes de terem uma ideia antecipada do que esperar desse encontro" (GOFFMAN, 2002, p.11). Isso se dá porque procuramos passar uma imagem a respeito de como gostaríamos de ser tratados. O indivíduo projeta

\footnotetext{
${ }^{3}$ Atividade bombeiro militar realizada diretamente no combate a incêndio ou no atendimento a vítimas de acidentes de modo geral, ou seja, as atividades realizadas externamente no contato com a sociedade ou com a natureza.
} 
Revista Científica do Corpo de Bombeiros Militar de Pernambuco

Seção 1 - Artigos Técnico Científicos

Artigo publicado no Vol.03 №06 - Edição de JAN a JUN 2017 - ISSN 2359-4829

Versão on-line disponível em: http://www.revistaflammae.com

então, de maneira a ser reconhecido pelos outros, uma representação exagerada daquilo que é, até que todos possam reconhecer suas características mais marcantes, as quais estão diretamente ligadas à sua personalidade. Descortinam-se, então, vários fatores que levam os indivíduos a estabelecerem relações de reciprocidade nas interações sociais, portanto,

Muitos fatos decisivos estão além do tempo e do lugar da interação, ou dissimulados nela. Por exemplo, as atividades "verdadeiras" ou "reais", as crenças e emoções do indivíduo só podem ser verificadas indiretamente, através de confissões ou do que parece ser um comportamento expressivo involuntário (GOFFMAN, 2002, p.12).

Os fatores observados na interação social são importantes para as relações interpessoais porque estabelecem a força com que serão criados os laços de afetividade entre os indivíduos, e depende da forma como são apresentados no momento da comunicação, ou seja, "o indivíduo terá que agir de tal modo que, com ou sem intenção, expresse a si mesmo, e os outros por sua vez, terão de ser de algum modo, impressionados por ele" (ICHHEISER, 1949 , p. 6-7). O cuidado que o indivíduo tem na forma com que apresenta a sua imagem é fundamental, uma vez que "quando um indivíduo se apresenta diante de outros, terá muitos motivos para procurar controlar a impressão que estes recebem da situação" (GOFFMAN, 2002, p. 23).

$\mathrm{Na}$ interação social, cada indivíduo procura controlar a sua própria imagem, que é transmitida para os outros membros da sociedade, de forma a facilitar sua aceitação como indivíduo acolhido e participativo num grupo no qual se busca ser inserido, e, com esse objetivo, vai construindo identidades adequadas a cada contexto e situação.

Não é provavelmente um mero acidente histórico que a palavra "pessoa", em sua acepção primeira, queira dizer máscara. Mas, antes, o reconhecimento do tato de que todo homem está sempre e em todo lugar, mais ou menos conscientemente, representando um papel. É nesses papéis que nos conhecemos uns aos outros, é nesses papéis que nos conhecemos a nós mesmos (PARK, 1950, p. 249). 
A forma como um indivíduo procura ser aceito em um grupo, a imagem que procura passar, leva a um entendimento sobre como os laços serão criados dentro de grupos específicos de profissionais que desempenham uma mesma função, repetidas vezes e com os mesmos integrantes, como no caso dos militares das guarnições de combate a incêndio do 1ํ Batalhão de Bombeiros Militar da Paraíba. Como destaca Goffman (2002, p. 27-28), quando se refere ao recruta novato que "segue a etiqueta do exército para evitar uma punição física e, finalmente, chega a seguir o regulamento para que sua organização não seja envergonhada e seus oficiais e companheiros $o$ respeitem". Sendo assim, o indivíduo procura replicar os comportamentos dos seus pares a fim de ser reconhecido como um deles.

De certa forma, somos levados então a acreditar que as regras militares, quando aplicadas a um grupo de indivíduos, como é o caso das guarnições operacionais do Corpo de Bombeiros Militar da Paraíba, em certo grau, acabam sendo internalizadas, forçando a interação social entre os bombeiros militares. Tem-se, pois, um padrão de comportamentos previamente estabelecido, uma vez que cada componente que se submete à carreira militar o faz sabendo que deverá manter uma postura aceita pelos demais integrantes do grupo em que estiver inserido. Esse comportamento adotado pelo novato não poderá ser desviante do que é considerado normal pela maioria, ou correrá então o risco de ser considerado divergente, dificultando assim sua aceitação como indivíduo acolhido e participante. Resulta disto que a adequação e aceitação dos novos recrutas em uma equipe de bombeiros militares dar-se-ão com a reprodução programada e consciente do comportamento dos integrantes mais antigos pelos mais novos.

Desse modo, o conceito das representações sociais apontado por Goffman (2002), no qual o indivíduo procura mostrar à sociedade somente aquilo que quer, se fortalece quando vemos que todos sentimos a necessidade de estarmos inseridos, ao mesmo tempo em que somos aceitos, em um grupo. 
Revista Científica do Corpo de Bombeiros Militar de Pernambuco

Seção 1 - Artigos Técnico Científicos

Artigo publicado no Vol.03 №06 - Edição de JAN a JUN 2017 - ISSN 2359-4829

Versão on-line disponível em: http://www.revistaflammae.com

Essa necessidade de aceitação levará, certamente, à interação social entre os indivíduos, a qual, por sua vez, acarretará em laços, e, por conseguinte, em relações de camaradagem e amizade. O próprio Goffman (2002, p. 81), em sua obra, revela que "é evidente que os indivíduos membros de uma mesma equipe se encontrarão, em virtude deste fato, em importantes relacionamentos uns com os outros". É por essa ótica que entendemos que o regime militar, em suas bases de criação, prevê, por meio de atributos morais como a honra, o respeito e o espírito de corpo, que os homens que compartilham suas vidas em uma caserna criem laços de amizade, os quais representam a necessidade dos mesmos de estarem inseridos no grupo. Esses atributos morais mobilizam o convívio entre os militares e, dessa maneira, a amizade em si se torna uma ferramenta facilitadora no enfrentamento de situações adversas e, consequentemente, no "cumprimento da missão".

A necessidade de permanecer inserido em um grupo que oferece proteção social leva o indivíduo a perder, sem perceber, controle sobre suas próprias ações. Uma vez que se faz parte de um grupo, deverá ser adotada a vontade da equipe. Assim sendo, o individualismo abre espaço para a coletividade. As vontades dos integrantes serão avaliadas, mas nem sempre estarão de acordo com o que se deseja, e nessas ocasiões, será preciso confiar no julgamento alheio.

Durante uma representação de equipe em andamento, qualquer participante tem o poder de abandoná-la ou interrompê-la por uma conduta não apropriada. Cada um é obrigado a confiar na boa conduta e no comportamento de seus companheiros, e vice-versa. Há, por conseguinte, um vínculo de dependência recíproca unindo os membros de uma mesma equipe aos outros (GOFFMAN, 2002, p 80).

Ainda que existam certas perdas na liberdade de comportamento e escolha do indivíduo, este se vê protegido no contexto em que se encontra,

\footnotetext{
${ }^{4}$ Para os militares, o "cumprimento da missão" pode ser entendido como a conclusão com êxito de um serviço ou ordem dada por superior hierárquico, ou ainda, por escrito em ordem de serviço, como também a execução da competência legal da instituição.
} 
afinal, o grupo traz mais vantagens do que desvantagens. O grupo torna-se, mesmo que de maneira inconsciente, como um lugar confortável, conhecido e seguro, pois, os companheiros de equipe, então, proporcionalmente à frequência com que agem como equipe e ao número de assuntos incluídos na proteção delineadora, tendem a ser ligados por direitos do que se poderia chamar de "familiaridade" (GOFFMAN, 2002, p. 81).

Este conceito de familiaridade só ratifica o comportamento dos profissionais que muitas vezes apontam sua profissão como uma segunda família, cenário que se repete e é comum nas instituições de regime militar, incluídos neste cenário os Corpos de Bombeiros Militares. Nesses grupos, as relações de familiaridade são, acima de tudo, uma condição de acolhida dos demais ao novo integrante do grupo.

Entre eles, o privilégio da familiaridade - que pode se constituir numa espécie de intimidade sem calor - não precisa ser algo de natureza orgânica, que se desenvolve vagarosamente com o passar do tempo em comum, mas é antes um relacionamento formal, automaticamente ampliado e recebido, tão logo o indivíduo tome lugar na equipe (GOFFMAN, 2002, p 81).

Conforme destacam Souza e Hutz (2008, p. 265) "a amizade pode ser definida também como um relacionamento interpessoal de mutualidade entre pessoas que não são familiares, parentes ou parceiras sexuais". De maneira geral, podemos dizer que há vários conceitos e descrições para as relações de companheirismo e amizade. Mas todas as descrições desse sentimento procuram evidenciar uma característica comum, aquela do bem que se recebe e o que se procura dar numa relação de amizade. O próprio Aristóteles (1984, p. 203) afirma que, "definimos um amigo como aquele que deseja e faz, ou parece desejar e fazer o bem no interesse de seu amigo". Essa definição evidencia o que cada indivíduo ganha, seja a satisfação pessoal ou o próprio afeto do semelhante, e dá por sua vontade, o mesmo que recebe, numa relação de amizade. $O$ filósofo segue ainda e complementa que o amigo pode 
ser "aquele que vive na companhia de um outro e compartilha com ele os mesmos pesares e alegrias de seu amigo" (1984, p. 203). Esse ponto citado por Aristóteles evidencia uma característica marcante dos indivíduos inseridos em um grupo de trabalho. Todos, certamente, em algum momento de suas carreiras, dividirão com seus amigos momentos de alegria e pesar, especialmente em uma carreira profissional como a de bombeiro militar.

As experiências comuns compartilhadas pelos indivíduos são fundamentais na construção de uma relação interpessoal de amizade, uma vez que tendemos a nos aproximar daquilo que conhecemos. Nesse aspecto, Aristóteles (1984, p. 182) acrescenta que, "com efeito, toda a amizade tem em vista o bem ou o prazer, e baseia-se numa certa semelhança. Cada um recebe de cada um a todos os respeitos o mesmo que dá, ou algo semelhante". Seguindo esse raciocínio, dizemos que o indivíduo entrega devoção e apoio ao seu amigo, porque espera receber dele o mesmo em troca, criando assim uma relação de mão dupla onde cada um dá e recebe nas mesmas proporções.

A relação de amizade então existe, e nela pode-se perceber as vantagens de possuir um amigo, alguém que esteja do seu lado para apoiar, para dividir fardos, compartilhar experiências, buscar consolo e ajuda, dividir felicidade e também tristeza, dividir não só sentimentos, mas sim trabalhos físicos e obrigações. São compromissos grandes demais para qualquer ser humano carregar sozinho, e a divisão de tais fardos alivia a própria existência. Tudo isso torna essa relação interpessoal ainda mais importante quando se fala de indivíduos inseridos em grupos de trabalho, já que essas características serão essenciais para que o profissional se sinta inserido em uma equipe que Ihe passe confiança e que esteja pronta para lhe dar suporte em momentos de dificuldade. 


\subsection{As relações de amizade em grupos de trabalho e no militarismo}

As interações sociais a que se submetem os indivíduos inseridos em grupos de trabalho serão cruciais na moldagem de uma relação de companheirismo e amizade. Baseado no tempo e na natureza da atividade que desempenham, a atividade em conjunto acarretará no compartilhamento de experiências, as quais podem ser momentos de alegria, mas certamente também momentos de tensão, pressão e estresse emocional. Esses momentos difíceis são apontados por Aristóteles não somente como catalizadores na criação de fortes laços de amizade, mas sim como artifícios utilizados pelo indivíduo para suportar as adversidades do trabalho, visto que, "a amizade é, pois, mais necessária na adversidade, e por esse motivo são os amigos úteis que buscamos em tal caso. Com efeito, a presença dos amigos é aprazível tanto na boa como na má fortuna, já que nossa dor é menor quando eles a compartilham conosco (ARISTÓTELES, 1984, p. 213).

Ainda nesse raciocínio, temos que a amizade, dentro de um grupo, juntamente com a familiaridade alcançada entre os membros de uma equipe, após um período longo de convivência, não será somente um artifício usado para a proteção individual do ser social, mas também, em sua essência, torna mais confortável a inserção dos seres humanos em grupos de trabalho.

A presença do amigo não faz somente nos sentirmos felizes, mas é necessária, não só porque o homem é um ser social, mas uma vez que, na condição de agentes absorvidos na própria ação, não temos a distância necessária que permite determinar o significado e valor pleno das ações e obter o prazer que acompanha a contemplação das ações boas, parte constitutiva da felicidade (ORTEGA, 2002, p. 41).

O que se percebe é que o sentimento de felicidade de um indivíduo, que está inserido em um grupo, pode estar relacionado à presença do amigo. 
Revista Científica do Corpo de Bombeiros Militar de Pernambuco

Seção 1 - Artigos Técnico Científicos

Artigo publicado no Vol.03 №06 - Edição de JAN a JUN 2017 - ISSN 2359-4829

Versão on-line disponível em: http://www.revistaflammae.com

Necessitamos da presença de um outro para o pleno convívio porque nossa posição não nos permite, sozinhos, entendermos as situações e o valor de nossas ações sem que um outro possa reagir de alguma forma, gerando assim um resultado emocional àquela ação desenvolvida por nós.

Talvez não seja possível mensurar o quão mais feliz está o indivíduo por encontrar-se parte integrante de um círculo de amizades, mas é inegável a importância de se conviver inserido em tal situação. Como diz Ortega (2002, p. 43), "Aristóteles estende as relações de amizade quase à totalidade das relações humanas, incluindo formas de parentesco, vínculos entre cidadãos na polis e relações de hospitalidade". Se a amizade então se estende em quase todas as relações, as interações de um grupo de trabalho certamente farão florescer laços entre os indivíduos, nos levando a afirmar que a própria natureza do regime militar é um catalisador para a formação de laços de afinidade entre os indivíduos. Outro ponto a ser analisado são as vantagens obtidas pelos indivíduos em um grupo de trabalho fechado, tais quais as guarnições operacionais de bombeiro militar.

$\mathrm{Na}$ Idade Média, os grupos de soldados a serviço do Rei existiam sob uma ética profissional em que "servir a um rei, uma dama, a seu Deus, ou ainda, a seu amigo, era a mais alta forma de liberdade, alguma coisa como o contrário da submissão" (GROS, 2009, p. 22). Ora, na visão do autor, estar inserido em um grupo não era uma forma de perder algum grau de liberdade, mas sim alcançar o mais alto grau de liberdade de escolhas, optar por dedicar sua vida a servir alguém em quem se acredite.

O dever nietschiano: a verdadeira liberdade é ser posto no desafio pelo outro ou por si, posto no desafio de obedecer, de cumprir. De um para o outro, é preciso que haja a altura, que só um outro pode nos impor. Ou então, tudo se reduz e a pessoa ser ela mesma se torna uma aventura tão pobre e vulgar como o que nos é vendido como desenvolvimento pessoal e felicidade de ser nós mesmos. É uma questão de dignidade. A dignidade enquanto repousa sobre 0 sentimento profundo de que nós valemos mais que nós mesmos (GROS, 2009, p. 23). 
O que se observa é que, na Antiguidade, estar inserido em um grupo resultava na satisfação pessoal. O sentimento de dignidade e obrigação para com o dever, na presença de outros que poderiam presenciar tais ações, era a materialização da felicidade. A figura do amigo aparece aqui como sendo o outro a quem o soldado de um exército recorre na busca de reconhecimento pelas suas ações.

Quando voltamos os nossos olhos ao Ocidente moderno, percebemos que a unidade da equipe durante uma suposta batalha se reconfigura, fazendo com que a realização pessoal de servir a si mesmo, ou a alguém a que se admire, se perde. O soldado moderno não é mais "romântico", não é mais uma unidade pela ética transcendental de servir. As motivações do soldado moderno são as mais variadas e vão, desde busca salarial, passando eventualmente pela satisfação profissional pessoal, até a falta de opções em seguir outra carreira profissional. Ainda assim, é inegável, porém, que a condição social do homem moderno, apesar de todas as formas de automação dos serviços humanos, ainda leva, numa equipe de trabalho, e em especial numa de serviço operacional, sob regime militar, à formação do contato entre os indivíduos.

As instituições modernas, sob regime militar, possuem em sua organização básica a disciplina e a hierarquia. Foquemos nossos olhares para a disciplina, visto que esta é apontada como a principal reguladora de comportamentos, e em análise detalhada, é a "arte de dispor em fila, e da técnica para a transformação dos arranjos. Ela individualiza os corpos por uma localização que não os implanta, mas os distribui e os faz circular numa rede de relações" (FOUCAULT, 2014, p. 143). O que se percebe é que a disciplina nas instituições total-disciplinares surge como artifício na criação das relações entre os indivíduos, uma vez que tais interações levam a uma unificação da tropa e, consequentemente, a uma melhor resposta na prestação do serviço a que se propõe aquela equipe. 
Ainda que as motivações dos indivíduos que adentram as fileiras de uma instituição militar sejam as mais diversas possíveis, ao ingressar nas carreiras militares, dada a forma como o Estado organiza essas instituições, os indivíduos serão forçados, quer seja pela alienação dos espaços exteriores aos ambientes de serviço, quer seja pelas interações a que serão submetidos em seus grupos de trabalho, a criar laços com os seus companheiros. Resta verificar se tais laços, criados dentro das instituições, e independente da forma com que surgiram, serão levados para além dos limites das instituições militaristas, gerando em primeiro lugar, um impacto social na vida pessoal dos indivíduos e, em segundo lugar, uma resposta na eficiência da prestação de serviços por parte daquele profissional.

\subsection{As relações de amizade e camaradagem na vida pessoal e profissional dos bombeiros militares da Paraíba}

Dado o caráter qualitativo dessa pesquisa, não haveria a possibilidade de alcançar resultados reais sem a consulta direta aos militares que fazem parte do serviço operacional do CBMPB. Dessa forma, no intuito de melhor compreender o que entendem aqueles que fazem o serviço operacional acerca das relações interpessoais entre os indivíduos, aplicamos um questionário com perguntas abertas, referentes à interação social, mais especificamente, sobre as relações interpessoais que acontecem entre bombeiros militares que trabalham no serviço considerado operacional.

No universo de um Batalhão de Combate à Incêndio, que conta com 03 (três) Unidades de Socorro, em João Pessoa, nas quais, em média, 05 (cinco) componentes concorrem a uma escala de $24 \mathrm{~h} / 72 \mathrm{~h}^{5}$, temos uma média total de

\footnotetext{
${ }^{5} \mathrm{~A}$ escala de serviço a que concorrem os militares do serviço operacional do CBMPB se configura em $24 \mathrm{~h}$ de serviço com um intervalo de $72 \mathrm{~h}$ de folga, podendo os militares, em sua folga, serem voluntários para uma escala extra remunerada, compreendida por $24 \mathrm{~h}$ de serviço.
} 
15 (quinze) militares escalados por dia. Assim, temos um total de 60 (sessenta) bombeiros militares para o serviço operacional de combate a incêndio somente na capital, todos eles Praças. Somado a esse número, temos mais 12 Oficiais Subalternos, Tenentes, que concorrem a uma escala de Comandante de Socorro de Unidade, atuando como supervisores das viaturas de combate a incêndio, totalizando 72 (setenta e dois) militares, entre Praças e Oficiais ${ }^{6}$. Nesse contexto, foram aplicados 30 (trinta) questionários, sendo 20 (vinte) deles aos Praças e 10 (dez) aos Oficiais, dos quais apenas 24 (vinte e quatro) foram devolvidos, e dos quais, apenas 22 (vinte e dois) foram respondidos satisfatoriamente ${ }^{7}$. A escolha pelos questionários deveu-se a uma tentativa de evitar o constrangimento de uma entrevista direta, feita por um superior hierárquico, no caso um Capitão, o que poderia gerar uma manipulação das respostas dadas pelos entrevistados. A escolha pelo questionário aberto, não identificado, pareceu então a alternativa que daria resultados mais reais.

Temos que ter em mente que a estratégia utilizada era apreender condições subjetivas de um questionário aberto, mesmo que nossa crença se baseie na condição de que uma entrevista aberta semiestruturada poderia ter sido um recurso metodológico mais eficaz (FRANÇA, 2015) para a elaboração deste tipo de pesquisa. Além disso, evitamos identificar os entrevistados por uma questão ético-científica de resguardar suas identidades.

Dessa forma, com base nas respostas apresentadas, podemos evidenciar algumas considerações. No que diz respeito ao que é considerado motivador pelos bombeiros militares, temos que a maioria baseia a sua motivação pessoal na oportunidade de salvaguardar vidas e bens alheios, bem

\footnotetext{
${ }^{6} \mathrm{O}$ quadro de integrantes do Corpo de Bombeiros Militar da Paraíba está dividido em Postos e Graduações, nas quais estão inseridos os Oficiais, no topo da pirâmide, que são considerados os gestores das atividades operacionais e administrativas da Corporação, bem como as Praças, inseridos na base da pirâmide, que podem ser considerados a massa operacional, os responsáveis diretos pelo cumprimento da atividade fim.

${ }^{7}$ Dos 24 (vinte e quatro) questionários respondidos 2 (dois) estavam incompletos, com respostas inconclusivas ou em branco.
} 
como obter o reconhecimento da sociedade por tal atividade. Como afirmam os entrevistados:

Considero motivador a própria atividade fim da corporação, ou seja, salvaguardar vidas e bens (Soldado BM Masculino 1).

O fato de poder guardar outras pessoas e receber o reconhecimento da sociedade (Cabo BM Masculino 1).

A possibilidade de salvar vidas e de oferecer uma melhor qualidade de vida às pessoas, sem ao menos conhece-las, e por conta disso ser reconhecido pela população ( $2^{\circ}$ Tenente BM Feminino 1).

As observações dos militares acerca das motivações, que eles mesmos enxergam na profissão, demonstram que o reconhecimento de outros indivíduos, acerca da importância da profissão que se executa, tem papel importante como motivador na labuta diária. Somado a isso, podemos destacar ainda o fato da maioria ver na própria atividade, qual seja, a de salvar vidas e bens alheios, um fator motivador para o trabalho.

Quando indagados ao fato de se trabalhar em equipe no Corpo de Bombeiros Militar da Paraíba, os militares entendem como sendo importante para a equipe de trabalho e para o próprio serviço. E sobre isso, podemos destacar:

Indispensável! Pois a guarnição cria um esforço coletivo para concluir com êxito a ocorrência (Soldado BM Feminino 1).

Acho que existe uma interação muito grande entre os militares, pois todos trabalham unidos em prol de um único resultado, garantir a preservação da vida e do patrimônio alheiros (1ํ Sargento BM Masculino 1).

Enxergo isso de maneira muito positiva, embora em todas as formas de trabalho ou emprego haja problemas de relacionamentos (Cabo BM Masculino 2).

Neste ponto, podemos observar que o trabalho em equipe é citado por todos como importante para o tipo de serviço que se desenvolve e para a atividade fim. É notável, porém, que alguns ainda acreditam haver algum 
Revista Científica do Corpo de Bombeiros Militar de Pernambuco

Seção 1 - Artigos Técnico Científicos

Artigo publicado no Vol.03 №06 - Edição de JAN a JUN 2017 - ISSN 2359-4829

Versão on-line disponível em: http://www.revistaflammae.com

problema de relacionamento entre os indivíduos, fato que é destacado pelos próprios entrevistados como estando dentro do normal e do aceitável.

$\mathrm{Na}$ tentativa de aprofundar o tema "trabalho em equipe", foi indagado o que cada um entendia por "espírito de corpo", e as respostas trazem um pouco da subjetividade do que se imagina:

É quando um grupo de pessoas trabalham juntas procurando atingir um determinado objetivo, se ajudando e defendendo a mesma causa

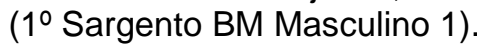

Todos trabalhando em prol de um mesmo objetivo, como um corpo humano em que cada um possui uma função ( $2^{\circ}$ Tenente Feminino 1).

Individualidades deixadas de lado, e a busca de uma uniformidade nas decisões em grupo (2o Tenente Feminino 2).

Todos trabalhando com o mesmo objetivo. Companheirismo. (Soldado BM Masculino 2).

Para Miaille (2010), a expressão "espírito de corpo" "remete à ideia ou à constatação, pelo próprio jogo da metáfora que ele constitui, de que o corpo precisa de uma alma ou um espírito para poder existir socialmente". O que se observa é que conforme a ideia que se faz, a expressão é realmente aquilo que procura dizer, e que se constata na resposta obtida com a aplicação do questionário, "espírito de corpo" é a unidade das partes trabalhando em conjunto para se constituir um todo forte e coeso. Podemos então extrair que todos aqueles que fazem parte de um grupo tem ideia do que o trabalho em equipe significa, trabalhar como uma unidade para um fim comum.

Ao abordar o que mais satisfazia cada um ao concluir com êxito uma ocorrência, as respostas indicaram um ponto de convergência. Todos demonstraram satisfação oriunda de saber que alguém se beneficiou com aquela ação. Aqui então vemos que o prazer daqueles que optam por servir à população, de alguma forma, vem quando a própria população se sente satisfeita com o serviço prestado. 
Em se tratando do escopo dessa pesquisa, as relações entre os indivíduos de uma mesma equipe, trabalhando em conjunto, e os laços que podem surgir, foi indagado se ao longo da carreira havia sido possível desenvolver laços com outros militares, Praças ou Oficiais, que extrapolaram a esfera profissional. As respostas apontam para aquilo que os teóricos abordados nesse artigo já demonstravam:

\footnotetext{
Sim. Com a convivência, seja em qualquer ramo de trabalho, acabamos construindo vínculos de amizade com as pessoas com as quais nos identificamos mais. Independente de patente, cargo ou função ( $1^{\circ}$ Tenente BM Feminino 1).

Sim. Foi possível desenvolver laços de amizades e laços afetivos. Pois no convívio diário criamos relações duradouras e saudáveis. Inclusive, meu futuro esposo conheci na academia de musculação do quartel (Soldado BM Feminino 1).

Sim, depende muito da mente dos novos colegas de profissão, onde eles podem enxergar a extensão do humano que trabalha com ele (Cabo BM Masculino 2).
}

Sim, várias amizades. A intimidade da convivência diária extrapola as paredes do quartel (1ํㅡㄹ Tenente BM Masculino 1).

O que se observa aqui pode ser interpretado como a constatação do objetivo dessa pesquisa. Há, apesar de toda a rígida estrutura que permeia um regime militar, embora isso tenha diminuído um pouco com o passar dos anos, e ainda mais por se tratar do Corpo de Bombeiros Militar, uma predisposição para a criação de laços de amizade e camaradagem nos indivíduos que se encontram inseridos numa instituição militarista, como é o caso de um quartel. Outro ponto a ser observado ainda, tendo sido citado inclusive nas respostas, é o fenômeno do convívio diário por parte dos indivíduos, este sim tendo sido apontado como determinante para a formação de laços, o que confirma o que já destacava Goffman em sua pesquisa sobre as interações sociais, "é evidente que os indivíduos membros de uma mesma equipe se encontrarão, em virtude deste fato, em importantes relacionamentos uns com os outros" (2014, p. 95). 
Adiante, com a finalidade de posteriormente desenvolver formas de aproximação entre os indivíduos, foi perguntado se era considerado que uma relação de proximidade fora da instituição, com um companheiro bombeiro, influenciava na atividade profissional. As respostas obtidas apontam para uma positividade, talvez já prevista na criação do regime militar:

\footnotetext{
Influencia sim, pois através desse contato muitos conhecimentos podem ser compartilhados e trazidos para o nosso dia a dia, oferecendo assim um serviço melhor para a população $\left(2^{\circ}\right.$ Tenente BM Feminino 1).

Sim, isso melhora muito na hora das ocorrências, devido a amizade você sempre quer fazer o melhor para o seu colega de trabalho (Cabo BM Masculino 3).

Sim, o ambiente muda. Você trabalha feliz, ao lado de pessoas que gosta e que sabe que gostam de você ( $3^{\circ}$ Sargento BM Masculino 1).

Sim, a confiança no outro aumenta. É diferente de trabalhar com uma pessoa que você não sabe quem é. Como é que você vai confiar nela? Ainda mais num tipo de serviço que pode custar a sua vida (1을 Tenente BM Masculino 1).
}

Vale destacar, porém, que ainda houve aqueles que dissessem que não há influência no resultado o fato de se trabalhar entre amigos, desde que todos estejam comprometidos com a causa. Esse posicionamento pode representar uma parcela do que se pensa sobre o tema, no entanto há que se verificar em que condições há o comprometimento da equipe, ainda que esta seja composta apenas de indivíduos com contatos estritamente profissionais. Entretanto, podemos verificar que há um impacto direto na resposta daqueles que conseguiram criar vínculos de amizade e camaradagem dentro da esfera profissional em que se encontravam. Sendo possível dizer inclusive, de acordo com as respostas, que o ambiente de trabalho entre amigos torna-se mais feliz e consequentemente mais prazeroso, refletindo diretamente na confiança mútua entre os integrantes do grupo, o que, na visão daqueles que responderam o questionário, acaba por melhorar o ambiente de trabalho. Nesse aspecto, o próprio Aristóteles disse, em se tratando do amigo, que "do 
homem bom também é verdadeiro dizer que pratica muitos atos no interesse de seus amigos e de sua pátria, e, se necessário, dá a vida por eles" (1984, p. 209). O filósofo já enxergava, nas relações de amizade, a confiança mútua que poderia ser desenvolvida com base nas relações entre os indivíduos. É dessa subjetividade advinda das relações entre os amigos que extraímos a importância desses laços para os serviços que dependem da confiança entre semelhantes, afinal, é muito mais confortável estar do lado de alguém que não hesitará prestar auxílio no momento em que precisarmos.

\section{CONSIDERAÇÕES FINAIS}

Foi possível, com base nesta pesquisa, estudar as interações sociais entre os indivíduos na criação dos laços de amizade e camaradagem em um grupo de trabalho. $O$ que esteve em evidência foi a análise dessas relações para compreendermos o nível de confiança dos integrantes de um grupo de trabalho sob influência do regime militar.

Para isso, situamos a compreensão da interação social como ferramenta na criação dos laços afetivos entre os indivíduos de uma sociedade, os quais, simplesmente pelo fato de viverem nesse modelo, possuem uma disposição prévia a desenvolverem o contato com seu semelhante.

Neste percurso, mostramos que os indivíduos que se encontram inseridos em instituições consideradas total-disciplinares são levados, pela natureza das ocupações de trabalho, a criar laços entre seus pares, facilitando assim as interações sociais dentro dessa estrutura. Ademais, passamos a descrever as estruturas existentes na criação dos laços de amizade e camaradagem em grupos de trabalho e no militarismo, no que se verificou a facilitação da familiaridade pelas condições deste tipo de regime. 
Revista Científica do Corpo de Bombeiros Militar de Pernambuco

Seção 1 - Artigos Técnico Científicos

Artigo publicado no Vol.03 №06 - Edição de JAN a JUN 2017 - ISSN 2359-4829

Versão on-line disponível em: http://www.revistaflammae.com

Oportunamente, confrontamos os resultados obtidos a partir dos estudos teóricos com a aplicação de um questionário aberto, aplicado aos integrantes do serviço operacional do Corpo de Bombeiros Militar da Paraíba, no intuito de verificar se houve a criação de laços de amizade e camaradagem entre os indivíduos, a forma como se deu o estabelecimento dessas relações e, por fim, se na visão dos próprios integrantes do serviço operacional do CBMPB houve influência significativa no ambiente de trabalho devido a esses laços criados entre os indivíduos.

Finalmente, em virtude dos resultados obtidos, é inegável que existe uma influência no ambiente de trabalho, na maneira com que os componentes se relacionam e na confiança mútua dos integrantes da tropa. Sendo assim, de posse desses resultados, novos estudos podem ser desenvolvidos no intuito de avaliar maneiras de se incentivar a criação desses laços com o objetivo de melhorar o ambiente de trabalho e, consequentemente, a qualidade do serviço prestado na atividade fim do Corpo de Bombeiros Militar do Estado da Paraíba.

\section{REFERÊNCIAS}

ARISTÓTELES. Ética A Nicômaco. Tradução de Leonel Vallandro e Gerd Bornheim. São Paulo: Abril S. A. Cultural, 1984.

FOUCAULT, Michel. Vigiar e Punir: história das violências nas prisões. Rio de Janeiro: Vozes, 2014.

FRANÇA, Fábio Gomes de. O ensino da sociologia nas instituições policiais militares: elementos para a crítica da ordem ou para uma ordem não crítica? In_FRANÇA, Fábio Gomes de; SANTOS, Carlos Eduardo Batista dos (orgs.). Estudos em Segurança Pública: Direitos Humanos, Polícia e Violência. João Pessoa: Ideia, 2015, p. 73-94.

GOFFMAN, Erving. Manicômios, Prisões e Conventos. 7 Ed. São Paulo: Perspectiva, 2001.

A Representação Social do Eu na Vida Cotidiana. 10 Ed. Petrópolis: Vozes, 2002. 
GROS, Frédéric. Estados de Violência: ensaio sobre o fim da guerra. Aparecida: Idéias \& Letras, 2009.

ICHHEISER, Gustav. Misunderstandings in human relations: a study in false social perception. Chicago, University of Chicago Press, 1949.

MIAILLE, Michel. Predisposições ao Espírito de Corpo: Os Candidatos ao Concurso da Magistratura. Tradução de Fernando de Castro Fontainha. Revista Ética e Filosofia Política, v 2, n 12, Julho de 2010.

ORTEGA, Francisco. Genealogias da Amizade. São Paulo: lluminuras, 2002.

PARK, Robert Ezra. Race and Culture. Glencoe III: The Free Press, 1950.

SOUZA, Luciana Karine de. HUTZ, Claudio Simon. Relacionamentos Pessoais e Sociais: Amizade em Adultos. Psicologia em Análise. Maringá, 2008, V. 13, p. 257-265. 